\title{
Risk factors for operated carpal tunnel syndrome: a multicenter population-based case-control study
} Stefano Mattioli ${ }^{1}$, Alberto Baldasseroni ${ }^{2}$, Massimo Bovenzi ${ }^{3}$, Stefania Curti ${ }^{1}$, Robin MT Cooke ${ }^{1}$, Giuseppe Campo ${ }^{4}$, Pietro G Barbieri ${ }^{5}$, Rinaldo Ghersi ${ }^{6}$, Marco Broccoli ${ }^{7}$, Maria Pia Cancellieri ${ }^{8}$, Anna Maria Colao ${ }^{9}$, Marco dell'Omo ${ }^{10}$, Pirous Fateh-Moghadam ${ }^{11}$, Flavia Franceschini ${ }^{12}$, Serenella Fucksia ${ }^{9}$, Paolo Galli13 , Fabriziomaria Gobba ${ }^{14}$, Roberto Lucchini ${ }^{15}$, Anna Mandes 12, Teresa Marras16, Carla Sgarrella17, Stefano Borghesi15, Mauro Fierro ${ }^{1}$, Francesca Zanardi ${ }^{1}$, Gianpiero Mancini ${ }^{* 7}$ and Francesco S Violante ${ }^{1}$

Address: ${ }^{1}$ Occupational Medicine Unit, Dipartimento di Medicina Interna, dell'Invecchiamento e Malattie Nefrologiche, University of Bologna, Bologna, Italy, ${ }^{2}$ Tuscany Regional Centre for Occupational Injuries and Diseases (CeRIMP), Florence, Italy, ${ }^{3}$ Institute of Occupational Medicine, University of Trieste, Trieste, Italy, ${ }^{4}$ Dipartimento Processi Organizzativi, National Institute of Occupational Safety and Prevention (ISPESL), Rome, Italy, ${ }^{5}$ Occupational Health Service, ASL di Brescia, Brescia, Italy, ${ }^{6}$ Occupational Health Service, ASL di Modena, Modena, Italy, ${ }^{7}$ Occupational Health Service, ASL di Ravenna, Ravenna, Italy, ${ }^{8}$ Occupational Health Service, ASUR Marche - Zona 2, Urbino, Italy, ${ }^{9}$ Occupational Health Service, ASUR Marche - Zona 6, Fabriano, Italy, ${ }^{10}$ Institute of Occupational Medicine and Toxicology, University of Perugia, Perugia, Italy, ${ }^{11}$ Epidemiology Unit, Azienda Provinciale per i Servizi Sanitari, Provincia Autonoma di Trento, Trento, Italy, ${ }^{12}$ Occupational Health Service, ASL di Bologna, Bologna, Italy, ${ }^{13}$ Occupational Health Service, ASL di Imola, Imola, Italy, ${ }^{14}$ Department of Public Health Sciences, University of Modena and Reggio Emilia, Modena, Italy, ${ }^{15}$ Occupational Medicine Institute, University of Brescia, Brescia, Italy, ${ }^{16}$ Occupational Health Service, ASL di Sassari, Sassari, Italy and ${ }^{17}$ Occupational Health Service, ASL di Firenze, Florence, Italy

Email: Stefano Mattioli - s.mattioli@unibo.it; Alberto Baldasseroni - alberto.baldasseroni@asf.toscana.it; Massimo Bovenzi - bovenzi@univ.trieste.it; Stefania Curti - stefania.curti@unibo.it; Robin MT Cooke - robinmtcooke@gmail.com; Giuseppe Campo - giuseppe.campo@ispesl.it; Pietro G Barbieri - pietro.barbieri@aslbrescia.it; Rinaldo Ghersi - r.ghersi@ausl.mo.it; Marco Broccoli -m.broccoli@ausl.ra.it; Maria Pia Cancellieri - mariapia.cancellieri@sanita.marche.it; Anna Maria Colao - medlavoro@asl6.marche.it; Marco dell'Omo - mdellomo@unipg.it; Pirous Fateh-Moghadam - Pirous.FatehMoghadam@apss.tn.it; Flavia Franceschini - flavia.franceschini@ausl.bo.it; Serenella Fucksia - serenellafucksia@libero.it; Paolo Galli - p.galli@ausl.imola.bo.it; Fabriziomaria Gobba - f.gobba@unimore.it; Roberto Lucchini - lucchini@med.unibs.it; Anna Mandes - anna.mandes@unibo.it; Teresa Marras - responsabile.spresal@aslsassari.it; Carla Sgarrella - carla.sgarrella@asf.toscana.it; Stefano Borghesi - stef.borghesi@libero.it; Mauro Fierro - maurofierro@libero.it; Francesca Zanardi - francesca.zanardi2@studio.unibo.it; Gianpiero Mancini* - gianpiero.mancini@unibo.it; Francesco S Violante - francesco.violante@unibo.it

* Corresponding author

Published: 16 September 2009

BMC Public Health 2009, 9:343 doi:10.1 186/147|-2458-9-343
Received: 12 November 2008

Accepted: 16 September 2009

This article is available from: http://www.biomedcentral.com//47I-2458/9/343

(C) 2009 Mattioli et al; licensee BioMed Central Ltd.

This is an Open Access article distributed under the terms of the Creative Commons Attribution License (http://creativecommons.org/licenses/by/2.0), which permits unrestricted use, distribution, and reproduction in any medium, provided the original work is properly cited.

\begin{abstract}
Background: Carpal tunnel syndrome (CTS) is a socially and economically relevant disease caused by compression or entrapment of the median nerve within the carpal tunnel. This population-based case-control study aims to investigate occupational/non-occupational risk factors for surgically treated CTS.
\end{abstract}

Methods: Cases $(n=220)$ aged 18-65 years were randomly drawn from 13 administrative databases of citizens who were surgically treated with carpal tunnel release during 200I. Controls 
( $n=356)$ were randomly sampled from National Health Service registry records and were frequency matched by age-gender-specific CTS hospitalization rates.

Results: At multivariate analysis, risk factors were blue-collar/housewife status, BMI $\geq 30 \mathrm{~kg} / \mathrm{m}^{2}$, sibling history of CTS and coexistence of trigger finger. Being relatively tall (cut-offs based on tertiles: women $\geq 165 \mathrm{~cm}$; men $\geq 175 \mathrm{~cm}$ ) was associated with lower risk. Blue-collar work was a moderate/strong risk factor in both sexes. Raised risks were apparent for combinations of biomechanical risk factors that included frequent repetitivity and sustained force.

Conclusion: This study strongly underlines the relevance of biomechanical exposures in both nonindustrial and industrial work as risk factors for surgically treated CTS.

\section{Background}

Carpal tunnel syndrome (CTS) is a socially and economically relevant disease caused by compression or entrapment of the median nerve within the carpal canal [1]. Probable risk factors for CTS include age [2], female gender [3], diabetes [4], hypothyroidism [5], obesity [6], family history of CTS [7], menopause [8] and concurrent pathologies such as rheumatoid arthritis [9]. Other factors that have been studied include low height $[10,11]$, smoking history [5], high parity [8], use of oral contraceptives [12], wrist fractures [9] and household chores [13]. Analysis of data from the population-based Occupational Supplement of the U.S. National Health Interview survey indicated that repetitive bending/twisting of the hands/ wrists and use of vibratory tools are important risk factors for CTS [14,15]. Moreover, a recent systematic review that considered many cross-sectional studies and some longitudinal/case-control studies found evidence of increased risk of CTS among workers exposed to regular/very repetitious wrist flexion/extension (especially when accompanied by a forceful grip) or to regular/prolonged use of hand-held vibratory tools [16]. Knowledge of the risks associated with job titles is limited (mainly deriving from cross-sectional studies) $[17,18]$. Few population-based case-control studies looking at both non-occupational and occupational risk factors for CTS are available $[19,20]$.

We performed a multicenter population-based case-control study on risk for surgically treated CTS designed to assess occupational factors (including job titles) alongside proposed non-occupational risk factors.

\section{Methods}

\section{Selection of participants}

Thirteen centers (local administrative authorities from central-northern Italy and Sardinia) participated in the study: the Provinces (Province) of Brescia, Modena, Perugia, Ravenna, Sassari and Trent; the Municipalities (Comuni) of Bologna and Florence; the Local Health Authorities (Unità Sanitarie Locali) of Fabriano, Imola, Urbino, and 'northern Bologna' and 'southern Bologna' (at the time, covering geographical areas to the north and south of the municipality). Each center identified 20 'cases' and 40 'controls', aged 18-65 yr. Identification of 'cases' was based on randomized sampling from their administrative databases containing discharge records from all local hospitals. In Italy, all public and private hospitals (including day-hospitals) are legally obliged to transmit to local authorities individual discharge records containing codified data for compulsory registration in administrative databases based on the patient's residence (irrespective of hospital location). The sampling frame comprised all residents who during the year 2001 had been admitted to hospital (irrespective of the place of treatment) with CTS as the principal diagnosis according to the International Classification of Diseases (ICD-9 code 3540) and who had been submitted to surgical treatment for carpal tunnel release (Diagnosis Related Group [DRG] code 06). At the time of the study, Italian regulations required that carpal tunnel release operations be conducted only on hospital premises. All patients undergoing this treatment had to be formally admitted to hospital--even if only for a few hours on an outpatient basis. Furthermore, diagnostic confirmation by nerve conduction studies was generally considered a prerequisite for carpal tunnel release. Selection of controls was based on random sampling from the national health service registries (Anagrafe Assistiti Servizio Sanitario Nazionale) covering each of the thirteen administrative centers included in the study (after frequency matching by age and gender. Of note, at the time of the study all subjects resident in Italy were automatically entitled to national health service membership. Each center received standardized instructions (from S.M. and A.B.) for frequency matching criteria, based on reported age-sex-specific rates of hospitalization for CTS [21] in conjunction with a database regarding incidence of surgically treated CTS in the general population of seven Italian Regions [22]. In particular, each Epidemiology Unit randomly drew 40 controls (32 women, 8 men) in eight age-sex categories (1834 yr: 4 women, 0 men; 35-44 yr: 6 women, 2 men; $45-54$ yr: 14 women, 2 men; 55-65 yr: 8 women, 4 men). Control subjects who had received surgical treatment for CTS 
were excluded. For both cases and controls, randomization was independently conducted by local Epidemiology Units. All participants provided informed consent. The study protocol was centrally approved by a Local Ethical Committee (Policlinico S. Orsola-Malpighi, Bologna) and conducted in accordance with the guiding principles of the 2004 version of the Declaration of Helsinki.

\section{Design of questionnaire}

We developed a structured questionnaire designed for assessment of a series of potential occupational and nonoccupational risk factors, based on those proposed in the literature. Requested information included date of birth; gender; height $(\mathrm{cm})$; weight $(\mathrm{kg})$; level of education (less than elementary school, elementary school, junior high school certificate, high school diploma, university degree); smoking status ('current' [cigarettes/day and duration in yr], 'ex' [with year of cessation], or 'never'), alcohol consumption (3 drinks/day or more, 1-2 drinks/ day, 3-6 drinks/wk, 1-2 drinks/wk, or 'never'); current sporting activities and hobbies (with titles and duration in yr); household chores (h/day); family history of CTS (specifying first degree relatives affected and occupations); medical history (for wrist fractures, diabetes mellitus, amyloidosis, gout, progressive systemic sclerosis, rheumatoid arthritis, systemic lupus erythematosus, thyroid disorders, trigger finger, and chronic renal failure); occupational history (previous and current job titles, together with task descriptions; year of retirement, if appropriate). Regarding biomechanical factors, participants were asked to specify for each (previous/current) job, whether it entailed 1) using hand-held vibratory tools; 2) making sustained forceful hand/wrist movements; 3 ) very frequent repetitive hand/wrist movements; 4) frequent movements in uncomfortable hand postures; 5) frequent pinching actions; 6) manual work provoking skin compression (ie reddening, calluses, blisters or boils). Additionally, women were asked to specify use of oral contraception ('current' [duration in yr], 'past' [with year of cessation], or 'never'); parity (with delivery years); menopause (with year). 'Cases' were asked to provide information on any previous surgery for CTS (specifying affected side and year); occupation at the time of onset of the CTS symptoms that led to surgery in 2001; subsequent change of job due to CTS [yes/no]; any post-intervention problems in resuming daily/occupational activities. 'Controls' had to specify any history of surgical treatment for CTS (to avoid inclusion of inappropriately identified controls). Before the present study, the entire questionnaire was piloted on a sample of 80 subjects with/without CTS [23].

\section{Administration of questionnaire}

The questionnaire was mailed in 2003 to addresses of all 780 participants (twice, when necessary). When a mailed response was not received, we tried to administer the questionnaire by phone: in each center, these interviews were conducted by a single trained interviewer who transcribed participants' responses to identical questionnaires without eliciting additional information. Participants who were still reluctant to collaborate were asked to respond to a brief questionnaire, which requested date of birth, gender, level of education, current/last job title, and reason for not replying to the main questionnaire. When no interview was feasible, the participant was classified as a non-respondent. For deceased subjects and those too ill to answer, the next of kin filled in the written questionnaire (or provided telephone responses). The questionnaire administration phase of the study was closed in 2004.

\section{Codification of questionnaire}

Job titles were coded (according to the European Union variant of the International Standard Classification of Occupations ISCO 88) [24] by three occupational physicians (A.B., M.F., S.M.) who were blind to case/control status. We chose to consider in the main analysis the prevalent job during the past 2 years or--for cases who changed task due to CTS--at the time of onset of symptoms (since a relatively brief exposure period seems to be sufficient to precipitate onset of CTS symptoms) [25]. The only unemployed participant (a control, who was formerly a blue-collar worker) was included in a miscellaneous blue-collar category comprising less frequent job titles. The only student participant (a control) was included in the white-collar category. Retired workers were categorized as ex-blue-/ex-white-collar based on their last job title. Computer use was inferred from the task descriptions reported in the questionnaire. Job-specific plausibility of each of the self-reported biomechanical risk factors was reviewed by a team of three occupational physicians with expertise in ergonomics (M.B., P.G.B., R.G.), who were blinded to case/control status. In addition to job titles and task descriptions, the team took into account age, gender, job-specific employment duration, and historical context. Self-reported risk factors that were considered implausible were reclassified for analytic purposes as "no exposure"; any implausible absence of exposure was also corrected.

\section{Statistical analysis}

After exclusion of non-eligible subjects, participants who responded to the full written questionnaire entered the main analysis, with the exception of retired workers who were considered in a separate analysis because of the absence of current professional exposure. For the main analysis of non-retired subjects, univariate analysis included the main occupational and non-occupational factors. Body mass index (BMI), family history of CTS, alcohol consumption, smoking status, parity, broad 
socio-occupational groupings (blue-collar, white-collar, housewives) and job title (prevalent in the last 2 years, or at the time of onset of symptoms) were considered as categorical variables. We grouped women's job titles into 15 categories (for men, meaningful job-title analysis was not feasible due to number limitations). Height and education were considered as binary variables, as were each of the co-existent diseases and biomechanical risk factors. Cut-offs for height of women and men were based on the upper tertiles of controls. The cut-off for level of education was high school certificate, which in Italy is conferred at $\sim 19$ years of age. We entered variables that reached $\mathrm{p}<0.1$ at univariate analysis in unconditional logistic regression models constructed to assess risk associated with: 1) broad socio-occupational categories (blue-collar/housewives vs. white-collar) alongside individual factors; and 2) women's job title categories (after adjusting for individual factors). Level of education was excluded from the models due to its strong association with broad socio-occupational groupings. White-collar workers were taken as the reference category for assessment of risks associated with broad socio-occupational categories and job titles. We estimated OR and 95\% confidence interval (95\%CI) according to Breslow and Day [26]. For the general model including all non-retired women and men (reported in Table 1), we decided to group housewives together with blue-collar workers, based on the rationale that the biomechanical work performed by full-time housewives is broadly analogous to that experienced in certain nonindustrial blue-collar jobs such as domestic cleaners or waiters. Based on age-/gender-related frequency differences in the frequency of CTS [9], we conducted separate multivariate analyses for women and men, and also for different age classes (based on tertiles; feasible only for women). Parity was considered only in analyses restricted to women. Number considerations led us to exclude some variables from certain models. For example, in the analysis of women by age groups, we had to exclude alcohol consumption, family history of CTS, several coexistent pathologies and parity. Whenever appropriate, we additionally adjusted for the frequency-matched variables (age and gender) to minimize residual confounding [27]; we also adjusted for center. For selected factors, we calculated the population attributable risk (PAR) with 95\% CI using the method described by Natarajan et al [28]. From the ergonomic standpoint, we analyzed the plausible selfreported biomechanical risk factors by constructing two unconditional logistic regression models assessing the risks associated with 1) different numbers and 2) various combinations of the six factors. For both these models, the reference category was absence of any plausible biomechanical risk factor. The combinations of risk factors we examined were based on frequency and ergonomic considerations, such as the relevance of force and repetitivity of hand/wrist movements [29]. We also constructed a model crossing $\geq 1$ plausible self-reported biomechanical factors (as a marker of biomechanical exposure) with blue-collar/housewife and white-collar status (taking white-collar workers without biomechanical factors as the reference category). The separate analysis of retired workers was based on multivariate assessment of blue- vs white-collar (reference category) history, again using an unconditional logistic regression model, after adjusting for individual factors. Of note, the decision to focus only on past occupational history was based on number considerations. Stata 9.0 SE (Stata Corporation, Texas, TX) was used for analysis.

\section{Results \\ Response}

Enrolment of the entire study population is summarized in Figures 1, 2 (see also Additional file 1). Of note, in only 1 'case' (and no 'control') was the questionnaire filled in by the next of kin. Response rates for cases and controls were not significantly different ( $\mathrm{p}=0.997$, chi-square test) among the 13 centers. None of the centers showed less than $65 \%$ response for cases or controls. The 227 'cases' (and 413 'controls') who responded to the full or brief questionnaire represented $87 \%$ (and 79\%) of all attempted contacts. After exclusion of responders to brief questionnaires and other non-eligible subjects (see Figure 1), 220 cases and 356 controls entered the main analysis. Mean ages were $48.3 \pm 9.2 \mathrm{yr}$ for women cases $(\mathrm{n}=184)$ and $48.0 \pm 9.1 \mathrm{yr}$ for women controls $(\mathrm{n}=286) ; 49.1 \pm 8.8$ yr for men cases $(n=36)$ and $51.9 \pm 9.0$ yr for men controls $(n=70)$. No difference in the distribution of cases and controls was found for age or gender, reflecting the frequency matching. Of note, the 45-54-yr age group accounted for $43 \%$ of all cases and $45 \%$ of controls. Cases and controls reported similar numbers of jobs $(2.6 \pm 1.5$ for cases vs $2.5 \pm 1.4$ for controls among women; $3.0 \pm 1.7$ for cases vs $2.6 \pm 1.3$ for controls among men).

\section{Non-retired subjects (main analysis)}

(see Additional file 2)

\section{Socio-occupational and individual factors}

The reference category comprised 153 white collar workers ( 19 cases and 134 controls), 85 of whom were administrative clerks ( 8 cases, 77 controls); no risk related to use of personal computers was apparent (stratifying by "no/ occasional", "non-continuous" or "continuous" use; data not shown). Table 1 reports univariate and multivariate analysis of socio-occupational class and individual factors within the entire non-retired population. At unconditional logistic regression analysis, significant risk factors were blue-collar/housewife status ( $\sim 7$-fold vs white-collar), BMI $\geq 30 \mathrm{~kg} / \mathrm{m}^{2}$ ( $\sim 3$-fold), sibling history of CTS ( 7 fold, with wide $\mathrm{CI})$, and coexistence of trigger finger $(\sim 3$ fold); rheumatoid arthritis was borderline ( 2-fold). At 
Table I: Risk factors for surgically treated CTS among non-retired subjects

\begin{tabular}{|c|c|c|c|c|}
\hline & & & Univariate & Multivariate* \\
\hline & $\begin{array}{c}\text { Cases } \\
(n=191)\end{array}$ & $\begin{array}{l}\text { Controls } \\
(n=286)\end{array}$ & OR (95\% Cl) & OR $(95 \% \mathrm{Cl})$ \\
\hline \multicolumn{5}{|l|}{ Socio-occupational status } \\
\hline White collar & 19 & 134 & 1.0 & 1.0 \\
\hline Blue collar/housewife $\nmid$ & 172 & 152 & $8.0(4.5-14.2)$ & $7.1(4.0-12.7)$ \\
\hline \multicolumn{5}{|l|}{$\mathrm{BMI}\left(\mathrm{kg} / \mathrm{m}^{2}\right)$} \\
\hline$<25$ & 80 & 167 & 1.0 & 1.0 \\
\hline $25-29$ & 69 & 91 & $1.6(1.0-2.4)$ & $1.4(0.9-2.4)$ \\
\hline$\geq 30$ & 41 & 25 & $3.4(1.9-6.1)$ & $3.3(1.6-6.6)$ \\
\hline \multicolumn{5}{|l|}{ Height, cm } \\
\hline$<165$ (women) or <175 (men) & 149 & 165 & 1.0 & 1.0 \\
\hline$\geq 165$ (women) or $\geq 175$ (men) & 41 & 121 & $0.4(0.2-0.6)$ & $0.5(0.3-0.8)$ \\
\hline \multicolumn{5}{|l|}{ Alcohol consumption } \\
\hline Never & 67 & 83 & 1.0 & 1.0 \\
\hline I-2 drinks/wk & 37 & 56 & $0.8(0.5-1.4)$ & $0.8(0.4-1.6)$ \\
\hline 3-6 drinks/wk & 11 & 26 & $0.5(0.2-1.1)$ & $0.4(0.1-1.1)$ \\
\hline I-2 drinks/day & 56 & 80 & $0.9(0.5-1.4)$ & $0.8(0.5-1.5)$ \\
\hline 3 drinks/day or more & 20 & $4 \mid$ & $0.6(0.3-1.1)$ & $0.7(0.3-1.6)$ \\
\hline \multicolumn{5}{|l|}{ Family history of CTS } \\
\hline None & 160 & 260 & 1.0 & 1.0 \\
\hline Father/mother & 15 & 22 & I.I (0.6-2.2) & $1.3(0.5-3.1)$ \\
\hline Sibling & 15 & 3 & $8.1(2.3-29.2)$ & $6.6(1.5-29.4)$ \\
\hline \multicolumn{5}{|l|}{ Rheumatoid arthritis } \\
\hline No & 160 & 267 & 1.0 & 1.0 \\
\hline Yes & 30 & 19 & $2.6(1.4-4.9)$ & $2.2(1.0-4.6)$ \\
\hline \multicolumn{5}{|l|}{ Trigger finger } \\
\hline No & 157 & 271 & 1.0 & 1.0 \\
\hline Yes & 33 & 15 & $3.8(2.0-7.3)$ & $2.7(1.3-5.8)$ \\
\hline \multicolumn{5}{|l|}{ Diabetes mellitus } \\
\hline No & 181 & 280 & 1.0 & 1.0 \\
\hline Yes & 9 & 6 & $2.3(0.8-6.7)$ & $2.6(0.7-8.7)$ \\
\hline \multicolumn{5}{|l|}{ Renal failure } \\
\hline No & 187 & 282 & 1.0 & \\
\hline Yes & 3 & 4 & I.I $(0.2-5.1)$ & \\
\hline \multicolumn{5}{|l|}{ Thyroid disorders } \\
\hline No & 163 & 253 & 1.0 & \\
\hline Yes & 27 & 33 & $1.3(0.7-2.2)$ & \\
\hline \multicolumn{5}{|l|}{ Wrist fractures } \\
\hline None & 180 & 262 & 1.0 & \\
\hline At least one & II & 24 & $0.7(0.3-1.4)$ & \\
\hline \multicolumn{5}{|l|}{ Smoking status } \\
\hline Never & 103 & 147 & 1.0 & \\
\hline Former & 31 & 65 & $0.7(0.4-1.1)$ & \\
\hline Current & 57 & 73 & I.I (0.7-1.7) & \\
\hline \multicolumn{5}{|l|}{ Education level } \\
\hline Below high school diploma & 152 & 138 & 1.0 & \\
\hline High school diploma or higher & 39 & 148 & $0.2(0.2-0.4)$ & \\
\hline
\end{tabular}

*Multivariate unconditional logistic regression model adjusted for socio-occupational status, BMI, height, alcohol, family history of CTS, rheumatoid arthritis, trigger finger and diabetes mellitus (ie all the variables apart from education level that reached $\mathrm{p}<0 . \mathrm{I}$ at univariate analysis), as well as age and gender (the two variables used for frequency matching, which were included to reduce residual confounding) and center.

tThe grouping of housewives with blue-collar workers was based on biomechanical considerations.

gender stratification (Table 2), blue-collar status turned out to be a strong risk factor in both women ( $\sim 9$-fold) and men ( 7-fold), while housewife status was also a risk factor ( $\sim 4$-fold) in women. Among women, it was feasible to perform age-stratification by tertiles (Table 3 ), which also happened to approximate pre-, peri- and post-menopausal age groupings. Blue-collar status appeared to be a risk factor in all three subgroups. Housewife status was an important factor in post-menopausal age. Individual factors appeared more relevant in younger women: in this 


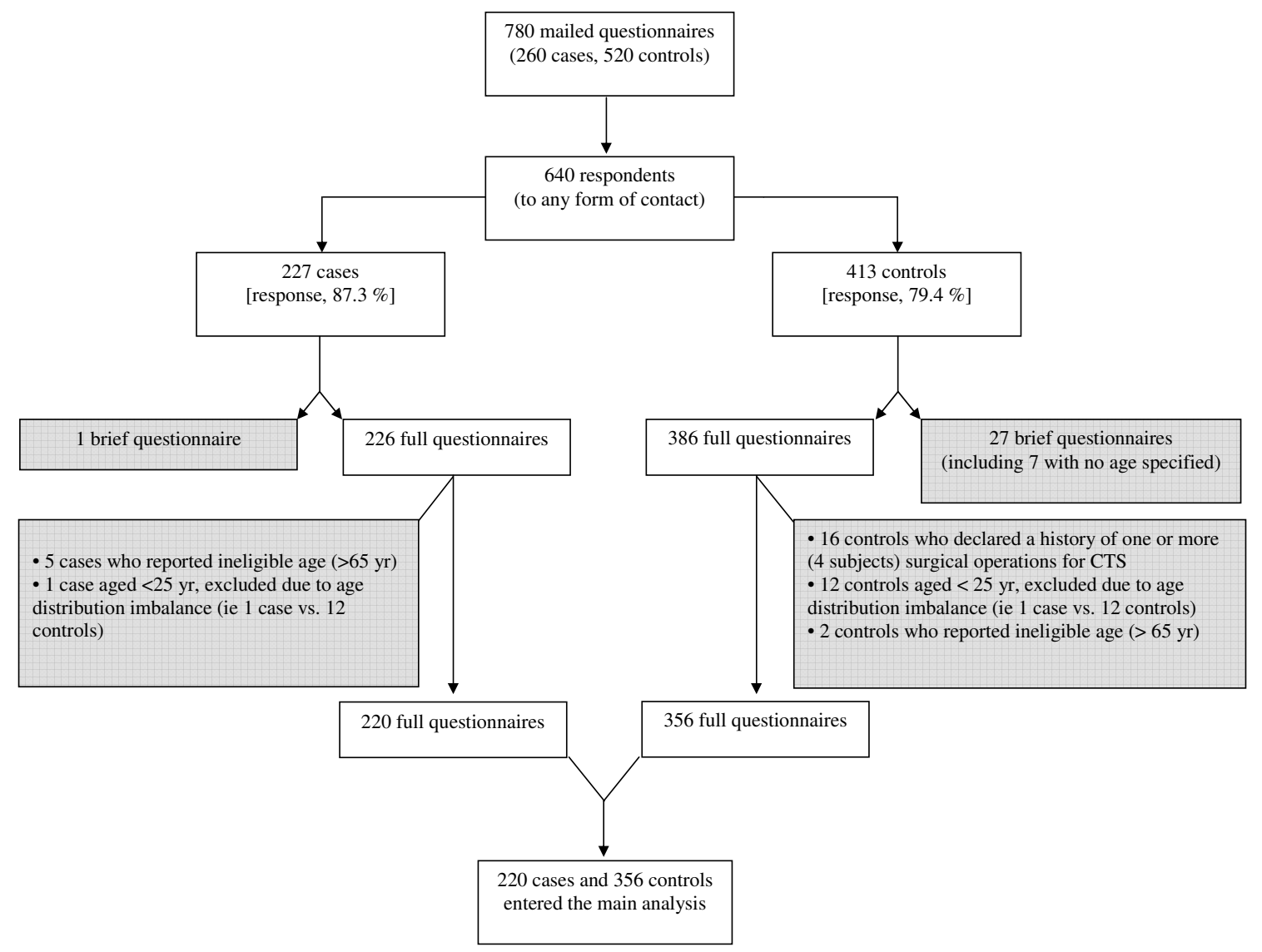

Figure I

Flow chart of data collection, exclusion criteria (excluded subjects are indicated in shaded boxes) and resulting groups used in data analysis.

subset, obesity was an important factor, whereas being relatively tall was associated with lower risk.

Table 4 reports results of an unconditional logistic regression model constructed for non-retired women to assess risks associated with blue-collar job titles (prevalent in the last 2 years or, for cases who changed task due to CTS, at the time of onset of symptoms). Raised OR were observed for food retail workers ( 30-fold vs white-collar workers), waiters/bartenders ( $\sim 20$-fold), cooks ( $\sim 17$-fold), agricultural/horticultural workers ( 13-fold), cleaners/domestic helpers ( $\sim 9$-fold), textile (mainly sewing-machine) workers ( $\sim$-fold), metal workers ( 9-fold), packaging workers ( 9-fold), and nursing/paramedical workers ( $\sim 8$-fold). Unsurprisingly given the relatively brief exposure period thought to be sufficient to precipitate onset of CTS symptoms [25], the magnitude of many of the professional associations turned out to be lower when job titles prevalent in the last 10 years or life-prevalent job titles were entered in the model (see Additional file 3).
The PAR for blue-collar work was 77\% (95\%CI, 30\%$99 \%$ ) among men and 78\% (95\%CI, 63\%-89\%) among women. The PAR for housewives (calculated among women) was 56\% (95\%CI, 31\%-77\%).

\section{Biomechanical risk factors}

Ergonomists blind to case/control status deemed that reclassification of one or more self-reported risk factors was necessary for 264 participants: in particular, 250 participants (114 cases, 136 controls) had one or more factors reclassified as "no exposure"; 18 participants (9 cases, 9 controls) had at least one factor reclassified as an "exposure"; 4 of the participants had factors reclassified in both directions. The distribution of each of the six biomechanical factors among the socio-occupational groups and blue-collar job title categories is shown in Additional file 4. Table 5 reports the results of an unconditional logistic regression model in which blue-collar/housewife and white-collar status were crossed with presence of $\geq 1$ biomechanical risk factor, a variable chosen as a broad marker of exposure. Raised risks were recorded for blue- 


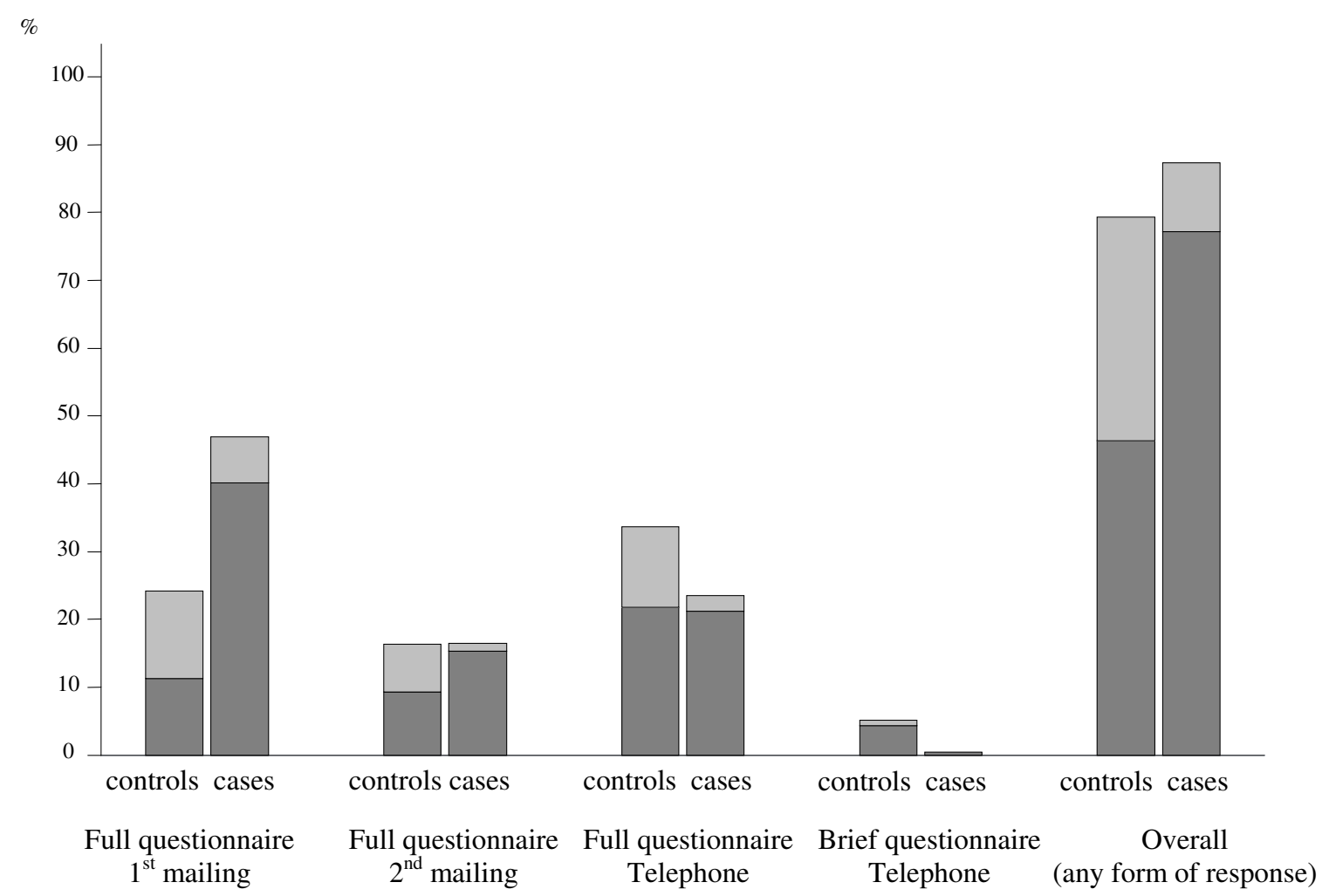

\section{Figure 2}

Proportions of case/control respondents according to blue-collar (dark shading) and white-collar status (light shading).

collar/housewife status both with and without biomechanical risk factors. However, the point estimates of the OR were about 2-fold higher in the "exposed" subgroups (ie exposed white-collar workers and exposed blue-collar workers/housewives) in comparison with their "unexposed" counterparts. Table 6 reports univariate and multivariate analysis of risks associated with different numbers/combinations of the factors (based on ergonomic and frequency considerations). No dose-response relation could be observed for exposure to increasing numbers of factors. However, incremental OR point estimates were apparent for combinations of biomechanical factors that included frequent repetitivity and sustained force.

\section{Retired subjects}

The reference category comprised 26 ex-white collar workers ( 4 cases, 22 controls). At multivariate analysis (adjusting for the individual factors considered in the model reported in Table 1), history of blue-collar work reached borderline significance as a predictor of surgically treated CTS (OR, 4.2; 95\% CI, 1.0-17.5). Number considerations precluded further analysis.

\section{Discussion}

This multicenter case-control study can be considered population-based since the cases were randomly drawn from comprehensive (obligatorily compiled) records of all operations performed by any Italian public or private hospital for patients residing within the territory covered by each administrative body. The work has the distinguishing feature that it considered both non-occupational and occupational factors, including job titles and biomechanical risk factors. Taken together, the results indicate that within the general population under study in our Italian centers risk of requiring surgically treated CTS resides mainly in the broad socio-occupational class of blue-collar workers, where manual work predominates. Notably, high OR were recorded for manual jobs in both the nonindustrial and industrial sectors.

After adjusting for BMI, height, and other non-occupational variables, the broad socio-occupational class of blue-collar workers and housewives appeared to have a 7 fold (point estimate) risk of surgical treatment for CTS, as compared with white-collar workers. Blue-collar work was associated with raised risks in both women and men. These findings are broadly in line with the results of a 
Table 2: Risk factors for surgically treated CTS among non-retired women and men

\begin{tabular}{|c|c|c|c|c|}
\hline \multirow[b]{2}{*}{ Women } & \multicolumn{3}{|r|}{ Univariate } & \multirow{2}{*}{$\begin{array}{l}\text { Multivariate* } \\
\text { OR }(95 \% \mathrm{CI})\end{array}$} \\
\hline & $\begin{array}{c}\text { Cases } \\
(n=163)\end{array}$ & $\begin{array}{l}\text { Controls } \\
(n=238)\end{array}$ & OR (95\% CI) & \\
\hline \multicolumn{5}{|l|}{ Socio-occupational status } \\
\hline White collar & 16 & 109 & 1.0 & 1.0 \\
\hline Blue collar & 101 & 71 & $9.7(4.9-19.2)$ & 9.1 (4.8-17.4) \\
\hline Housewife & 46 & 58 & $5.4(2.7-10.9)$ & $4.4(2.1-9.2)$ \\
\hline \multicolumn{5}{|l|}{$\mathrm{BMI}\left(\mathrm{kg} / \mathrm{m}^{2}\right)$} \\
\hline$<25$ & 74 & 154 & 1.0 & 1.0 \\
\hline $25-29$ & 56 & 60 & $1.9(1.2-3.1)$ & $1.8(1.1-3.1)$ \\
\hline$\geq 30$ & 32 & 21 & $3.2(1.7-6.0)$ & $3.9(1.9-8.1)$ \\
\hline \multicolumn{5}{|l|}{ Height, cm } \\
\hline$<165$ (women) or $<175$ (men) & 126 & 144 & 1.0 & 1.0 \\
\hline$\geq 165$ (women) or $\geq 175$ (men) & 36 & 94 & $0.4(0.3-0.7)$ & $0.5(0.3-0.8)$ \\
\hline \multicolumn{5}{|l|}{ Parity } \\
\hline None & 29 & 54 & 1.0 & 1.0 \\
\hline I & 42 & 80 & $1.0(0.5-1.8)$ & $0.8(0.4-1.6)$ \\
\hline 2 & 62 & 76 & $1.5(0.9-2.7)$ & $1.4(0.7-2.9)$ \\
\hline 3 or more & 30 & 28 & $2.0(1.0-4.0)$ & $1.4(0.6-3.3)$ \\
\hline Men & $(n=28)$ & $(n=48)$ & & \\
\hline \multicolumn{5}{|l|}{ Socio-occupational status } \\
\hline White collar & 3 & 25 & 1.0 & 1.0 \\
\hline Blue collar & 25 & 23 & $9.1(2.1-39.2)$ & $7.4(1.7-33.2)$ \\
\hline Housewife & -- & -- & -- & -- \\
\hline \multicolumn{5}{|l|}{ BMI $\left(\mathrm{kg} / \mathrm{m}^{2}\right)$} \\
\hline$<25$ & 6 & 13 & 1.0 & 1.0 \\
\hline $25-29$ & 13 & 31 & $0.9(0.3-2.9)$ & $0.6(0.1-2.4)$ \\
\hline$\geq 30$ & 9 & 4 & $4.9(0.9-25.8)$ & $3.8(0.6-25.7)$ \\
\hline \multicolumn{5}{|l|}{ Height, cm } \\
\hline$<165$ (women) or <175 (men) & 23 & 21 & 1.0 & 1.0 \\
\hline$\geq 165$ (women) or $\geq 175$ (men) & 5 & 27 & $0.2(0.0-0.6)$ & $0.2(0.0-0.6)$ \\
\hline \multicolumn{5}{|l|}{ Parity } \\
\hline None & -- & -- & -- & -- \\
\hline 1 & -- & -- & -- & -- \\
\hline 2 & -- & -- & -- & -- \\
\hline 3 or more & -- & -- & -- & -- \\
\hline
\end{tabular}

*Unconditional logistic regression models adjusted for socio-occupational status, BMI, height, age, center and (for women only) parity.

study by Rossignol et al of surgical interventions for CTS recorded on the Quebec Health Insurance database [30]. In the present study, full-time housewives (an important socio-occupational category accounting for $29 \%$ of all adult women in Italy) [31] also had a raised risk (4-fold point estimate). Unsurprisingly, biomechanical exposure was common among both blue-collar workers and housewives (see Additional file 4). After adjusting for potential confounders, blue-collar worker/housewives who reported at least one plausible biomechanical risk factor appeared to have about twice the risk of surgically treated CTS with respect to their "unexposed" counterparts. Furthermore, the few biomechanically "exposed" white-collar workers showed a non-significant point estimate of 2fold risk with respect to "unexposed" white-collar workers
(Table 5). Taken together, these observations seem to spotlight the etiologic relevance of exposure to ergonomic factors within an occupational context. Indeed, substantial PAR were recorded for women/men blue-collar workers and housewives, broadly in line with those (adjusted only for age and sex) recorded for manual workers in Montreal [30].

It should be underlined that due to the collection of only binary biomechanical data, it cannot be assumed that those workers/housewives who did not report risk factors were truly unexposed. Thus, it is difficult to distinguish a possible biomechanical contribution in the apparently "unexposed" subjects from other socio-occupationally related (eg psychosocial) factors. Of note, malingering is 
Table 3: Risk factors for surgically treated CTS in different age groups of non-retired women

\begin{tabular}{|c|c|c|c|c|}
\hline \multirow[b]{2}{*}{ Women $<45 \mathrm{yr}$} & \multicolumn{3}{|r|}{ Univariate } & \multirow{2}{*}{$\begin{array}{l}\text { Multivariate* } \\
\text { OR }(95 \% \mathrm{CI})\end{array}$} \\
\hline & $\begin{array}{c}\text { Cases } \\
(n=53)\end{array}$ & $\begin{array}{l}\text { Controls } \\
(n=82)\end{array}$ & OR $(95 \% \mathrm{Cl})$ & \\
\hline \multicolumn{5}{|c|}{ Socio-occupational status } \\
\hline White collar & 5 & 44 & 1.0 & 1.0 \\
\hline Blue collar & 42 & 26 & I $4.2(4.2-48.6)$ & $12.3(3.9-39.3)$ \\
\hline Housewife & 6 & 12 & $4.4(1.1-18.1)$ & $2.5(0.5-13.8)$ \\
\hline \multicolumn{5}{|l|}{$\mathrm{BMI}\left(\mathrm{kg} / \mathrm{m}^{2}\right)$} \\
\hline$<25$ & 26 & 66 & 1.0 & 1.0 \\
\hline $25-29$ & 18 & 11 & $4.2(1.7-10.5)$ & $4.0(1.3-12.5)$ \\
\hline$\geq 30$ & 9 & 5 & $4.6(1.3-15.7)$ & $8.4(1.6-43.9)$ \\
\hline \multicolumn{5}{|l|}{ Height, cm } \\
\hline$<165$ & 38 & 34 & 1.0 & 1.0 \\
\hline$\geq 165$ & 15 & 48 & $0.3(0.1-0.6)$ & $0.3(0.1-0.7)$ \\
\hline Women 45-5 I yr & $(n=5 I)$ & $(n=85)$ & & \\
\hline \multicolumn{5}{|c|}{ Socio-occupational status } \\
\hline White collar & 8 & 43 & 1.0 & 1.0 \\
\hline Blue collar & 33 & 22 & $8.1(2.8-23.0)$ & $7.7(2.8-2 \mathrm{I} .1)$ \\
\hline Housewife & 10 & 20 & $2.7(0.9-8.1)$ & $2.6(0.8-8.6)$ \\
\hline \multicolumn{5}{|l|}{ BMI $\left(\mathrm{kg} / \mathrm{m}^{2}\right)$} \\
\hline$<25$ & 25 & 54 & 1.0 & 1.0 \\
\hline $25-29$ & 16 & 25 & $1.4(0.6-3.1)$ & $1.6(0.6-3.9)$ \\
\hline$\geq 30$ & 10 & 4 & $5.4(1.4-20.2)$ & $6.0(1.4-25.4)$ \\
\hline \multicolumn{5}{|l|}{ Height, cm } \\
\hline$<165$ & 41 & 56 & 1.0 & 1.0 \\
\hline$\geq 165$ & 10 & 29 & $0.5(0.2-1.1)$ & $0.6(0.2-1.5)$ \\
\hline Women $\geq 52$ yr & $(n=59)$ & $(n=7 I)$ & & \\
\hline \multicolumn{5}{|c|}{ Socio-occupational status } \\
\hline White collar & 3 & 22 & 1.0 & 1.0 \\
\hline Blue collar & 26 & 23 & $8.3(1.9-35.7)$ & $9.9(2.3-42.6)$ \\
\hline Housewife & 30 & 26 & $8.5(2.0-35.7)$ & $9.5(2.3-39.9)$ \\
\hline \multicolumn{5}{|l|}{ BMI $\left(k g / m^{2}\right)$} \\
\hline$<25$ & 23 & 34 & 1.0 & 1.0 \\
\hline $25-29$ & 22 & 24 & $1.4(0.6-3.0)$ & $1.2(0.5-2.9)$ \\
\hline$\geq 30$ & 13 & 12 & $1.6(0.6-4.2)$ & $1.5(0.5-4.4)$ \\
\hline \multicolumn{5}{|l|}{ Height, cm } \\
\hline$<165$ & 47 & 54 & 1.0 & 1.0 \\
\hline$\geq 165$ & 11 & 17 & $0.7(0.3-1.8)$ & $0.8(0.3-2.2)$ \\
\hline
\end{tabular}

*Unconditional logistic regression models adjusted for socio-occupational status, BMI, height, age and center.

unlikely to have exerted much influence on these findings given the case definition of surgically treated CTS: any "invented" cases would have to pass through a stringent preoperative clinical workup including nerve conduction studies.

Few non-cross-sectional analytical studies have assessed associations between job titles and risk of CTS in the general population. In the present work, analysis of job titles was feasible only for women (due to number considerations). The findings must be interpreted in the context of the employment characteristics of the general population in the various centers. In particular, our reference category of women white-collar workers mainly comprised clerks who appeared to have little biomechanical exposure. It should be underlined that this study does not provide information regarding the highly relevant occupational category of data processors [30], who were poorly represented in the general population of the areas under study. Moreover, many industrial job titles were poorly represented due to regional employment characteristics (the 95\% CI for specific job titles and other occupational subgroups tended to be wide due to limited absolute numbers). Although most studies of occupational risk of CTS 
Table 4: Risks of surgically treated CTS associated with job titles prevalent in the last 2 years* among non-retired women

\begin{tabular}{|c|c|c|c|c|c|}
\hline & & & & Univariate & Multivariate $\dagger$ \\
\hline & ISCO codes & $\begin{array}{c}\text { Cases } \\
(n=163)\end{array}$ & $\begin{array}{l}\text { Controls } \\
(n=238)\end{array}$ & OR $(95 \% \mathrm{Cl})$ & OR $(95 \% \mathrm{Cl})$ \\
\hline White collar & $\begin{array}{c}\text { I, 2I, } 22 \text { (not 2230), } 23 \text { (not 2332), 24, } \\
3|I, 3| 2,315,32 \text { (not } 3225 \text { or } 323), 341 \text {, } \\
342,343,346,4 \mid \text { (not } 4|3| \text { or } 4 \mid 32 \text { ), } 42 \\
\text { (not } 4211), 516\end{array}$ & 16 & $109 \ddagger$ & 1.0 & 1.0 \\
\hline Food retail workers & 5221 & 8 & 2 & $27.3(4.3-173.2)$ & $29.8(5.6-159.7)$ \\
\hline Miscellaneous blue-collar workers & $\begin{array}{c}4|3 I, 4| 32,7 \mid, 724,73,74 I, 7421,7442 \\
822,823,8240,825,8266,827,8282 \\
8285,931\end{array}$ & 14 & 5 & $19.1(5.0-72.6)$ & $21.4(6.0-76.8)$ \\
\hline Waiters/bartenders & 5123 & 6 & 2 & $20.4(3.2-129.0)$ & $20.2(3.4-119.5)$ \\
\hline Cooks & 5122 & 8 & 3 & $18.2(3.7-88.7)$ & $17.2(3.7-78.8)$ \\
\hline Agricultural/horticultural workers & 61,9211 & 10 & 4 & $\mid 7.0(4 .|-7| .3)$ & $\mid 3.3(3.5-5 \mid .3)$ \\
\hline Cleaners and domestic helpers & 9131,9132 & 13 & 8 & II.I (3.5-34.6) & $9.2(3.1-27.6)$ \\
\hline Textile (mainly sewing-machine) workers & 826 & 5 & 4 & $8.5(1.9-37.7)$ & $9.2(2.0-42.4)$ \\
\hline Metal workers & $721,722,723,812,8211,8281$ & 5 & 4 & $8.5(1.9-37.7)$ & $9.0(2.0-39.6)$ \\
\hline Packaging workers & 9320 & 7 & 5 & $9.5(2.5-36.8)$ & $8.7(2.3-33.2)$ \\
\hline Nurses and paramedical workers & $2230,3225,323,5132,5133$ & 9 & 7 & $8.8(2.6-29.2)$ & $7.9(2.5-25.3)$ \\
\hline Miscellaneous service sector workers & $\begin{array}{c}4211,5141,5220,83,911,9133,914 \\
915,916\end{array}$ & 10 & 14 & $4.9(1.8-13.4)$ & $4.7(1.7-12.9)$ \\
\hline Housewives & 5121 & 46 & 58 & $5.4(2.7-10.9)$ & $4.4(2.1-9.1)$ \\
\hline Tailors & 743 & 4 & 6 & $4.5(1.1-18.5)$ & $3.5(0.8-14.9)$ \\
\hline Pre-primary school workers & $2332,3320,5131$ & 2 & 7 & $1.9(0.4-10.3)$ & $2.3(0.4-12.5)$ \\
\hline
\end{tabular}

*For cases who changed task due to CTS, we considered the patient's job title at the time of onset of symptoms.

fUnconditional logistic regression model adjusted for the individual factors entered in the multivariate model reported in Table 2 (ie. BMI, height, parity, age and center).

łlncludes I student.

have focused on industrial settings [17], some at-risk "non-industrial" occupational job titles have also been reported, including housekeepers/cleaners, food/beverage service workers, grocery store workers, postal workers, health workers, lorry/bus drivers, and child care workers $[14,30,32]$. In the present work, raised risks of surgically treated CTS were recorded in several clearly non-industrial blue-collar categories: food retail workers, waiters/bartenders, cooks, agricultural/horticultural workers (including many in the fruit-growing sector), cleaners/domestic helpers, and nursing/paramedical workers (with point estimates between about 8 and 30, albeit with wide 95\% CI). In a seminal article based on a hospital case series, Phalen noted that the majority of his patients were housekeepers or cooks [33]. More recently, Rossignol et al found that housekeeping occupations (including both commercial and domestic categories) appeared to be associated with a particularly risk of surgically treated CTS [30]. A previous Italian case-control study focusing on job tasks reported significantly raised risks of hospital-treated CTS for waiters/bartenders and cooks [34]. Of note, bartenders in Italy are commonly exposed to repetitive wrist actions

Table 5: Risk of surgically treated CTS in socio-occupational categories stratified according to biomechanical exposure (in terms of at least I plausible risk factor)

\begin{tabular}{|c|c|c|c|c|}
\hline & & & Univariate & Multivariate* \\
\hline & Cases & Controls & OR (95\% CI) & OR $(95 \% \mathrm{CI})$ \\
\hline \multicolumn{5}{|c|}{ White-collar workers } \\
\hline Not exposed & 16 & 122 & 1.0 & 1.0 \\
\hline Exposed & 3 & 12 & $1.9(0.5-7.6)$ & $2.1(0.5-9.5)$ \\
\hline \multicolumn{5}{|c|}{ Blue-collar/housewife status } \\
\hline Not exposed & 66 & 93 & $5.4(2.8-10.3)$ & $5.1(2.6-9.9)$ \\
\hline Exposed & 106 & 59 & I $3.7(6.6-28.3)$ & $12.8(6.4-25.3)$ \\
\hline
\end{tabular}

*Unconditional logistic regression model adjusted for the individual factors entered in the multivariate model reported in Table I (ie BMI, height, alcohol, family history of CTS, rheumatoid arthritis, trigger finger and diabetes), as well as age, gender and center. 
(a characteristic jerk) to operate espresso coffee machines, and this factor could at least partially explain the recorded excess risk. From an ergonomic standpoint, it is noteworthy that many plausible biomechanical risk factors were reported by cooks, waiters/bartenders, food retail workers and agricultural/horticultural workers, but not by nurses/ paramedics or cleaners/domestic helpers (see Additional file 4). However, it is possible that the collection of binary variables for biomechanical risk factors missed frequent medium/low-grade exposures. In general, we think that non-industrial job titles, particularly in the service sector) deserve more attention in CTS risk evaluation studies, including ergonomic evaluations.

The high OR recorded for nurses and paramedical workers could be attributable to several factors in addition to biomechanical risk factors, including possible facilitated access to surgical treatment for hospital workers. Nurse anesthetists are thought to be especially exposed to risk factors for CTS [35], but we have no way of knowing how many, if any, of the cases in the present study had this specific job title.

The roughly 4-fold increases of risk recorded for full-time housewives may also be at least partially attributed to ergonomic factors (despite the relative paucity of reported biomechanical risk factors). Although some residual confounding with parity and especially BMI is possible, we think that the contribution of domestic cleaning activities deserves consideration. In particular, it is reasonable to suppose that chronic biomechanical exposure might at least partially explain the high risk recorded among older housewives (Table 3). A case-control study on clinically/ electromyographically diagnosed CTS among Chinese women in Beijing concluded that certain manual household tasks could be associated with increased risk of CTS [13].

Although the exploratory analysis of plausible selfreported biomechanical risk factors (Table 6) was limited by the binary data collection and frequency considerations, the results are intriguing. The lack of a doseresponse relation for exposure to different numbers of risk factors is in line with the concept that some of these factors selected from the available ergonomic literature [1417] are particularly relevant $[17,29]$. Number considerations permitted us to explore combinations of just four of the main candidates: sustained force, frequent repetitivity, awkward posture, and palmar compression (unfortunately, use of vibratory tools was relatively rare in the study population). We dedicated particular attention to force and frequency because these two aspects form the basis of the official instrument developed by the American Conference of Governmental Industrial Hygienists (ACGIH) for objective evaluation of biomechanical hand/ wrist load (and values exceeding the hand activity limit have been associated with high rates of symptomatic CTS [36]). Strikingly, combinations that included these two factors (with or without awkward posture and palmar compression) were always associated with particularly high OR (Table 6). These findings reinforce concepts that have previously emerged from cross-sectional and cohort studies regarding the etiologic relevance of forceful and/or very repetitive manual work [14-16,36,37].

Table 6: Risks of surgically treated CTS associated with different numbers/combinations of biomechanical risk factors (use of vibratory tools; forceful hand/wrist movements; frequent repetitive hand/wrist movements; uncomfortable hand postures; frequent pinching actions; skin compression) among non-retired subjects

\begin{tabular}{|c|c|c|c|c|}
\hline & & & Univariate & Multivariate* \\
\hline & $\begin{array}{c}\text { Cases } \\
(n=191)\end{array}$ & $\begin{array}{l}\text { Controls } \\
(n=286)\end{array}$ & $\begin{array}{c}\text { OR } \\
(95 \% \mathrm{Cl})\end{array}$ & $\begin{array}{c}\text { OR } \\
(95 \% \mathrm{Cl})\end{array}$ \\
\hline No risk factor & 82 & 215 & 1.0 & 1.0 \\
\hline I risk factor & 48 & 42 & $3.0(1.8-4.9)$ & $2.8(1.6-4.8)$ \\
\hline Either force or frequency & 41 & 33 & $3.3(1.9-5.6)$ & $3.2(1.7-5.8)$ \\
\hline Any other factor & 7 & 9 & $2.0(0.7-5.7)$ & $1.4(0.5-4.6)$ \\
\hline 2 risk factors & 23 & 9 & $6.7(2.9-15.6)$ & $7.1(2.9-17.4)$ \\
\hline Any 2 factors from: force, frequency and posture & 15 & 4 & $9.8(3.0-31.9)$ & $10.3(3.0-35.1)$ \\
\hline Other combinations (of 2 risk factors) & 8 & 5 & $4.2(1.3-13.4)$ & $4.0(I . I-14.8)$ \\
\hline $3-4$ risk factors & 31 & 17 & $4.8(2.4-9.3)$ & $4.5(2.1-9.3)$ \\
\hline At least 3 factors from: force, frequency, posture and compression & 16 & 3 & $14.0(3.7-52.2)$ & $14.9(3.9-57.6)$ \\
\hline Other combinations (of 3 or 4 risk factors) & 15 & 14 & $2.8(1.3-6.1)$ & $2.2(0.9-5.5)$ \\
\hline $5-6$ risk factors & 7 & 3 & $6.1(1.5-24.8)$ & $5.0(1.1-22.6)$ \\
\hline
\end{tabular}

*The results derive from two separate multivariate unconditional logistic regression models (evaluating numbers/combinations of risk factors). Each model was adjusted for the individual factors entered in the multivariate model reported in Table I (ie BMI, height, alcohol, family history of CTS, rheumatoid arthritis, trigger finger and diabetes mellitus), as well as age, gender and center.

†Reference category. 
Regarding non-occupational variables, obesity has already been widely implicated as a risk factor for CTS in both cohort and case-control studies $[3,5]$ with global increases in risk broadly similar to those recorded in the present study. Among women, obesity-related risk of surgically treated CTS appeared to be highest in the lowest age tertile ( $<45$ years) (Table 3 ). A study exploring the relationship between obesity, age and CTS among patients registered at a neurophysiology department [38] found higher obesityrelated risks in younger age groups for both women and men (the limited number of men in our study precluded meaningful analysis). Such age-related differences could be attributed to different underlying pathogenetic mechanisms for CTS in younger and older people [38]. By contrast, at least among the women, blue-collar sociooccupational status appeared to be a risk factor at all ages.

In two hospital-based case-control studies, taller individuals appeared to have a lower risk of CTS $[10,11]$. In the present population-based study, relatively tall women and men (as defined by the upper tertiles of women and men controls) also turned out to be associated with lower risk (with point estimates of about 0.5 for women over $165 \mathrm{~cm}$ and men over $175 \mathrm{~cm}$ tall), even after adjusting for BMI and other possible risk factors. Even inclusion of level of education in the model (data not shown) to try to reduce social class-related bias [39] did not substantially change the results. Remarkably, even among white-collar workers, height appeared to be associated with reduced risk (point estimate, 0.2; data not shown). No interaction was found between height and BMI (data not shown). Height could be a marker of specific anthropometric characteristics of the forearm, wrist and hand [6]. Square wrist shape is a proposed risk factor for CTS [40]. Height-related size variations of tendons and muscles might also play a role.

Regarding parity, a roughly 2-fold (point estimate) excess risk of surgically treated CTS was recorded at univariate analysis for women with three or more children, but no significant association was detectable at multivariate analysis. An excess of risk was reported in a nested case-control study [41]. Our results should not have been affected by CTS during pregnancy (a phenomenon presumably influenced by physiological changes in hormone production and body mass): in line with the findings of a dedicated cohort study [42], very few cases in the study population ( $\mathrm{n}=4$; not shown) were submitted to surgery during pregnancy or in the year after childbirth. Along with possible residual confounding with BMI, biomechanical exposure during domestic work could at least partially explain the apparent excess risk associated with high parity (of note, women workers who had more children reported more hours of domestic chores; see Additional file 2). Alterna- tive explanations could involve long-term pathophysiologic effects of multiple pregnancies.

Lack of association between smoking habits and CTS was expected [9]. Our results provide some indication that light consumption of alcohol (3-6 drinks per week) might conceivably be protective: we think that information on drinking habits should be collected in epidemiologic studies of CTS, especially in view of the anti-inflammatory properties of red wine [43], which is widely consumed in our geographic setting. Another possible association which needs to be tested in larger studies regards surgical treatment for CTS in siblings. This putative risk factor could be attributed either to genetic and/or familial environmental factors. Unfortunately, our questionnaires did not provide information on the number of subjects with or without siblings (or numbers of siblings). Nevertheless, the finding of an almost 7 -fold excess risk in subjects with an affected sibling is particularly interesting in the light of a study of female twins which suggested that up to half the risk of CTS in women may be genetically determined [7].

Remarkably similar OR values were generally recorded at univariate and multivariate analysis suggesting a relative lack of confounding among different risk factors (except perhaps for high BMI in young women). In all age groups, both men and women blue-collar workers (in industrial/ non-industrial settings) turned out to be at increased risk of surgical treatment for CTS. We think it likely that biomechanical factors (which are more frequently encountered in manual blue-collar occupations) influence onset of CTS in both genders at almost any age.

\section{Study limitations}

It should be underlined that the sample size was not large enough to address many of the study objectives with confidence. The suggestive findings emerging from the present work require confirmation in appropriately sized studies, and also in geographic settings with different employment characteristics. Indeed, as noted above, many relevant job titles were either poorly represented or absent in our limited sample. For instance, the very high risks recorded for the broad blue-collar category may partially be attributed to the relative absence of intensive keyboard/mouse users such as data processors in the study sample.

In view of the relatively good but not ideal response $(74 \%)$ to the full questionnaire among potential controls, non-response bias may have influenced the main findings regarding socio-occupational status. Although this factor could have led to a slight overestimate of the risks associated with blue-collar/housewife status, it seems unlikely that the 7-fold excess risk could be mainly attributable to blue-collar/housewife non-responders among controls. 
Recall bias also requires consideration in case-control studies, especially when participants are aware of objectives and their case/control status. Although differential recall may not have influenced reporting of socio-occupational category or job titles, it could have affected the analyses involving biomechanical risk factors. Interpretation of these analyses is also affected by the decision to use binary variables for biomechanical data collection and classification (see discussion above). Expert ergonomists blindly reviewed the plausibility of the self-reported biomechanical risk factors and frequently modified exposure status; it should be borne in mind that the study participants received no guidance on how to interpret the descriptions of the biomechanical factors in the questionnaire (eg regarding what constitutes "frequent pinching actions"). Remarkably, a supplemental analysis (data not shown) of the self-reported biomechanical risk factors before the ergonomists' plausibility evaluations generated results substantially similar to those reported in Table 6 .

The risk estimates reported in the present study regard surgically-treated CTS and cannot automatically be extended to all clinically relevant cases of CTS. In the general population of Siena (Tuscany) $[22,44]$, surgical treatment seems to be performed in no more than about half the patients with an electromyographically confirmed diagnosis of symptomatic CTS (Table 7). In Siena at least, surgically treated patients [45] seem to have a more severe clinical and electrophysiological profile than untreated patients. In other respects, however, the characteristics of the two groups [45] appear broadly similar apart from a slightly lower level of education among the patients not submitted to surgical treatment. This knowledge seems to attenuate the legitimate concern that blue-collar workers, housewives and mothers of several children might have greater incentives to undergo surgical decompression of the median nerve in order to remain fit for essential manual activities (whereas male white-collar workers might be better placed to avoid particular tasks and postpone or avoid surgical treatment). We think that use of 'surgicallytreated CTS' as a case definition may provide (in Italy at least) a heuristic tool to help spotlight more clinically severe and socially relevant disease. Nevertheless, it must be stressed that a case definition of 'surgically-treated CTS' will presumably lead to identification of risk factors for having "CTS-related troubles" severe enough to warrant surgery (rather than just experiencing the disease itself). The higher risks recorded for manual workers could at least partially stem from this consideration.

\section{Conclusion}

In summary, this population-based case-control study highlights the relevance of biomechanical exposures encountered in non-industrial as well as industrial bluecollar work as risk factors for surgically treated CTS in
Table 7: Comparison of crude and sex-specific incidence rates (per 100,000 person-years) of CTS diagnosed by clinical symptoms plus electromyography (EMG) in the province of Siena for 1997-1998 [44] with in-hospital rates recorded [22] in the same province and period

\begin{tabular}{ccccc}
\hline & & Symptoms/EMG [44] & In-hospital [22] & Ratio \\
\hline 1997 & Women & 478.6 & 244.2 & 2.0 \\
& Men & 161.4 & 68.4 & 2.4 \\
& Overall & 326.5 & 159.9 & 2.0 \\
\hline \multirow{2}{*}{1998} & Women & 497.8 & 193.9 & 2.6 \\
& Men & 178.5 & 57.7 & 3.1 \\
& Overall & 344.5 & 128.5 & 2.7 \\
\hline
\end{tabular}

both sexes, and among different age groups of women. By contrast, associations with factors such as BMI and height seem to vary with age and gender. Until now, attention has mainly been focused on manual work in the industrial sector. We think more attention should be dedicated to evaluation of possible causal contributions of certain manual job tasks in the non-industrial sector in the etiology of severe CTS. If confirmed in larger studies, such considerations could be pertinent for prevention of socially/ clinically relevant morbidity, and also for adjudication of workers' compensation insurance claims.

\section{Competing interests}

The authors declare that they have no competing interests.

\section{Authors' contributions}

$\mathrm{SM}, \mathrm{AB}$ and $\mathrm{GM}$ designed the study with $\mathrm{SC}, \mathrm{MdO}, \mathrm{FG}, \mathrm{RL}$, and MBo.

$\mathrm{AM}, \mathrm{TM}, \mathrm{CS}, \mathrm{SB}, \mathrm{MBr}, \mathrm{RG}, \mathrm{PGB}, \mathrm{MPC}, \mathrm{AMC}, \mathrm{FF}, \mathrm{SF}, \mathrm{MdO}$, $P G$, PFM were responsible for supervising data collection in the different centers. SM, SC and GC were responsible for data analysis. SM, SC and RMTC drafted the manuscript and contributed to interpretation, together with $\mathrm{AB}$, $\mathrm{MF}, \mathrm{FZ}, \mathrm{MBo}$ and FSV. FSV supervised the entire work. All authors critically revised the manuscript. All authors read and approved the final manuscript.

\section{Additional material}

\section{Additional file 1}

Distribution of response modalities among the 780 attempted contacts (260 for cases, 520 for controls), and distributions of level of education and professional category among respondents.

Click here for file

[http://www.biomedcentral.com/content/supplementary/14712458-9-343-S1.pdf] 


\section{Additional file 2}

Summary statistics of selected individual factors (and hours of housework) according to gender and socio-occupational category.

Click here for file

[http://www.biomedcentral.com/content/supplementary/1471-

2458-9-343-S2.pdf]

\section{Additional file 3}

Risks of surgically treated CTS associated with job titles prevalent in the last 10 years and lifetime among non-retired women.

Click here for file

[http://www.biomedcentral.com/content/supplementary/1471-

2458-9-343-S3.pdf]

\section{Additional file 4}

Numbers (percentages) of workers exposed to different biomechanical risk factors by socio-occupational status and blue-collar job titles. Click here for file

[http://www.biomedcentral.com/content/supplementary/14712458-9-343-S4.pdf]

\section{Acknowledgements}

This study was partially funded by the National Institute for Occupational Safety and Health (Istituto Superiore per la Prevenzione e la Sicurezza sul Lavoro, ISPESL), Piano di attività 2002, Dipartimento Documentazione Informazione e Formazione: "Metodi di raccolta delle informazioni sui settori lavorativi a maggior rischio di STC in Italia"; and Regione Emilia-Romagna, Programma di Medicina del Lavoro. The work of Stefania Curti was partially supported by the Epidemiology Master's course at the University of Turin.

\section{References}

I. Katz JN, Simmons BP: Clinical practice. Carpal tunnel syndrome. N Engl ] Med 2002, 346: |807-|8|2.

2. Atroshi I, Gummesson C, Johnsson R, Ornstein E, Ranstam J, Rosén I: Prevalence of carpal tunnel syndrome in a general population. JAMA 1999, 282:153-158.

3. Nathan PA, Istvan JA, Meadows KD: A longitudinal study of predictors of research-defined carpal tunnel syndrome in industrial workers: findings at 17 years. J Hand Surg Br. 2005, 30(6):593-598.

4. Becker J, Nora DB, Gomes I, Stringari FF, Seitensus R, Panosso JS, Ehlers JC: An evaluation of gender, obesity, age and diabetes mellitus as risk factors for carpal tunnel syndrome. Clin Neurophysiol 2002, I I3:|429-|434.

5. Karpitskaya Y, Novak CB, Mackinnon SE: Prevalence of smoking, obesity, diabetes mellitus, and thyroid disease in patients with carpal tunnel syndrome. Ann Plast Surg 2002, 48:269-273.

6. Boz C, Ozmenoglu M, Altunayoglu V, Velioglu S, Alioglu Z: Individual risk factors for carpal tunnel syndrome: an evaluation of body mass index, wrist index and hand anthropometric measurements. Clin Neurol Neurosurg 2004, 106:294-299.

7. Hakim AJ, Cherkas L, El Zayat S, MacGregor AJ, Spector TD: The genetic contribution to carpal tunnel syndrome in women: a twin study. Arthritis Rheum 2002, 47:275-279.

8. Ferry S, Hannaford P, Warskyj M, Lewis M, Croft P: Carpal tunnel syndrome: a nested case-control study of risk factors in women. Am / Epidemiol 2000, I 5 I:566-574.

9. Geoghegan JM, Clark DI, Bainbridge LC, Smith C, Hubbard R: Risk factors in carpal tunnel syndrome. J Hand Surg $[\mathrm{Br}]$ 2004, 29:315-320.

10. Dieck GS, Kelsey JL: An epidemiologic study of the carpal tunnel syndrome in an adult female population. Prev Med 1985, 1 4:63-69.

II. De Krom MC, Kester AD, Knipschild PG, Spaans F: Risk factors for carpal tunnel syndrome. Am J Epidemiol 1990, I 32: I I02-IIIO.
12. Vessey MP, Villard-Mackintosh L, Yeates D: Epidemiology of carpal tunnel syndrome in women of childbearing age. Findings in a large cohort study. Int J Epidemiol 1990, 19:655-659.

13. Tang $X$, Zhuang L, Lu Z: Carpal tunnel syndrome: a retrospective analysis of 262 cases and a one to one matched case-control study of $6 \mathrm{I}$ women pairs in relationship between manual housework and carpal tunnel syndrome. Chin Med J 1999. I I 2:44-48.

14. Tanaka S, Wild DK, Seligman PJ, Halperin WE, Behrens VJ, PutzAnderson V: Prevalence and work-relatedness of selfreported carpal tunnel syndrome among U.S. workers: analysis of the Occupational Health Supplement data of 1988 National Health Interview Survey. Am J Ind Med 1995, 27:45I-470.

15. Tanaka S, Wild DK, Cameron LL, Freund E: Association of occupational and non-occupational risk factors with the prevalence of self-reported carpal tunnel syndrome in a national survey of the working population. Am J Ind Med 1997, 32:550-556.

16. Palmer KT, Harris EC, Coggon D: Carpal tunnel syndrome and its relation to occupation: a systematic literature review. Occup Med (Lond) 2007, 57:57-66.

17. Bernard BP: Hand/wrist musculoskeletal disorders (carpal tunnel syndrome, tendinitis, hand-arm vibration syndrome): evidence for work-relatedness. Musculoskeletal Disorders (MSDs) and Workplace Factors. A Critical Review of Epidemiologic Evidence for Work-Related Musculoskeletal Disorders of the Neck, Upper Extremity, and Low Back 1997 [http://www.cdc.gov/niosh/docs/97-|41/ ergotxt5a.html]. DHHS (NIOSH) Publication No. 97-I4I accessed I5 July, 2009

18. Hagberg M, Morgenstern H, Kelsh M: Impact of occupations and job tasks on the prevalence of carpal tunnel syndrome. Scand J Work Environ Health 1992, 18:337-345.

19. Nordstrom DL, Vierkant RA, DeStefano F, Layde PM: Risk factors for carpal tunnel syndrome in a general population. Occup Environ Med 1997, 54:734-740.

20. Giersiepen K, Eberle A, Pohlabeln H: Gender differences in carpal tunnel syndrome? Occupational and non-occupational risk factors in a population-based case-control study. Ann Epidemiol 2000, 10:481.

21. Liss GM, Armstrong C, Kusiak RA, Gailitis MM: Use of provincial health insurance plan billing data to estimate carpal tunnel syndrome morbidity and surgery rates. Am J Ind Med 1992, 22:395-409.

22. Mattioli S, Baldasseroni A, Curti S, Cooke RM, Bena A, de Giacomi G, dell'Omo M, Fateh-Moghadam P, Melani C, Biocca M, Buiatti E, Campo G, Zanardi F, Violante FS: Incidence rates of in-hospital carpal tunnel syndrome in the general population and possible associations with marital status. BMC Public Health 2008, 8:374.

23. Mancini G, Ehrlich S, Mattioli S, Mussuto V, Guerra A, Fucksia S, Ghini $M$, Violante FS: Sindrome del tunnel carpale e attività lavorativa: uno studio caso-controllo. Atti del IX Congresso di professione medica del comprensorio imolese: Imola Maggio 2000; Italy 2000:33-38.

24. ISCO 88 (COM) - the European Union variant of ISCO 88 (International Standard Classification of Occupations) [http://www2.warwick.ac.uk/fac/soc/ier/research/isco88/]. accessed I5 July, 2009

25. European Commission, Employment \& social affairs, Health \& safety at work: Information notices on diagnosis of occupational diseases EUR $14768 \mathrm{EN} ; 1997$.

26. Breslow NE, Day NE: Statistical Methods in Cancer Research Volume I. Lyon: International Agency for Research on Cancer; 1980.

27. Kirkwood BR, Sterne JAC: Linking analysis to study design: summary of method. In Essential Medical Statistics 2nd edition. Oxford, UK: Blackwell Publishing; 2003:410-4I2.

28. Natarajan S, Lipsitz SR, Rimm E: A simple method of determining confidence intervals for population attributable risk from complex surveys. Stat Med 2007, 26:3229-3239.

29. ACGIH: TLVs and BEls Cincinnati, OH: American Conference of Governmental Industrial Hygienists; 2008.

30. Rossignol M, Stock S, Patry L, Armstrong B: Carpal tunnel syndrome: what is attributable to work? The Montreal study. Occup Environ Med 1997, 54:519-523.

31. National Institute of Statistics (ISTAT): General population data. [http://www.istat.it/dati/db siti/]. accessed I5 July, 2009 
32. Osorio AM, Ames RG, Jones J, Castorina J, Rempel D, Estrin W, Thompson D: Carpal tunnel syndrome among grocery store workers. Am J Ind Med 1994, 25:229-245.

33. Phalen GS: The carpal-tunnel syndrome. Seventeen years' experience in diagnosis and treatment of six hundred fiftyfour hands. J Bone Joint Surg Am 1966, 48:2 I I-228.

34. Baldasseroni A, Tartaglia R, Carnevale F: Rischio di sindrome del tunnel carpale in alcune attività lavorative. Med Lav 1995, 86:34I-35I.

35. Diaz JH: Carpal tunnel syndrome in female nurse anesthetists versus operating room nurses: prevalence, laterality, and impact of handedness. Anesth Analg 2001, 93:975-980.

36. Violante FS, Armstrong TJ, Fiorentini C, Graziosi F, Risi A, Venturi S, Curti S, Zanardi F, Cooke RM, Bonfiglioli R, Mattioli S: Carpal tunnel syndrome and manual work: a longitudinal study. J Occup Environ Med 2007, 49: I 189-1 I96.

37. Werner RA, Franzblau A, Gell N, Hartigan AG, Ebersole M, Armstrong TJ: Incidence of carpal tunnel syndrome among automobile assembly workers and assessment of risk factors. J Occup Environ Med 2005, 47: 1044-1050.

38. Bland JD: The relationship of obesity, age, and carpal tunnel syndrome: more complex than was thought? Muscle Nerve 2005, 32:527-532.

39. Addor V, Wietlisbach V, Narring F, Michaud PA: Cardiovascular risk factor profiles and their social gradient from adolescence to age 74 in a Swiss region. Prev Med 2003, 36:217-228.

40. Kamolz LP, Beck H, Haslik W, Högler R, Rab M, Schrögendorfer KF, Frey $M$ : Carpal tunnel syndrome: a question of hand and wrist configurations? J Hand Surg [Br] 2004, 29:32I-324.

4I. Roquelaure Y, Mechali S, Dano C, Fanello S, Benetti F, Bureau D, Mariel J, Martin YH, Derriennic F, Penneau-Fontbonne D: Occupational and personal risk factors for carpal tunnel syndrome in industrial workers. Scand J Work Environ Health 1997, 23:364-369.

42. Mondelli M, Rossi S, Monti E, Aprile I, Caliandro P, Pazzaglia C, Romano C, Padua L: Long term follow-up of carpal tunnel syndrome during pregnancy: a cohort study and review of the literature. Electromyogr Clin Neurophysiol 2007, 47:259-27I.

43. Szewczuk LM, Penning TM: Mechanism-based inactivation of COX-I by red wine m-hydroquinones: a structure-activity relationship study. I Nat Prod 2004, 67: I777-I782.

44. Mondelli M, Giannini F, Giacchi M: Carpal tunnel syndrome incidence in a general population. Neurology 2002, 58:289-294.

45. Mondelli M, Aprile I, Ballerini M, Ginanneschi F, Reale F, Romano C, Rossi S, Padua L: Sex differences in carpal tunnel syndrome: comparison of surgical and non-surgical populations. Eur J Neurol 2005, I 2:976-983.

\section{Pre-publication history}

The pre-publication history for this paper can be accessed here:

http://www.biomedcentral.com/1471-2458/9/343/pre pub
Publish with Biomed Central and every scientist can read your work free of charge

"BioMed Central will be the most significant development for disseminating the results of biomedical research in our lifetime. "

Sir Paul Nurse, Cancer Research UK

Your research papers will be:

- available free of charge to the entire biomedical community

- peer reviewed and published immediately upon acceptance

- cited in PubMed and archived on PubMed Central

- yours - you keep the copyright

Submit your manuscript here:

http://www.biomedcentral.com/info/publishing_adv.asp
BiolMedcentral 